\title{
Mapeando los estudios visuales en América Latina: puntos de partida, anclajes institucionales e iniciativas
}

\author{
MAPPING VISUAL STUDIES IN LATIN AMERICA: STARTING POINTS, INSTITUTIONAL \\ ANCHORS AND INITIATIVES \\ MAPEAMENTO DOS ESTUDOS VISUAIS NA AMÉRICA LATINA: PONTOS DE PARTIDA, \\ ANCORAGENS INSTITUCIONAIS E INICIATIVAS
}

\section{Marta Cabrera*}

Editora invitada

La cultura es menos el paisaje que vemos que la mirada con la que lo vemos

Martín-Barbero

Este texto esboza, de manera muy esquemática y sin pretensiones de exhaustividad, un par de ejercicios que resultan necesarios, desde mi punto de vista, para situar y delinear los contornos del campo de los estudios visuales. Los ejercicios aquí propuestos son, en primera instancia, un recorrido por algunas pistas conceptuales, teóricas y metodológicas sobre lo visual, entendido en un sentido amplio, es decir, no limitado o centrado necesariamente en "la imagen" y enunciadas en el contexto latinoamericano de manera contemporánea con la emergencia del discurso y el campo de los estudios en las academias norteamericana y alemana en los años noventa (McPhail, 2011). El segundo ejercicio, por su parte, pretende rastrear algunas líneas que permitan observar conexiones e influencias del campo de los estudios visuales con programas, centros, trabajos académicos y otros elementos en el ámbito latinoamericano. De esta forma, la intención última de este texto es dar cuenta de las emergencias locales de preocupaciones y preguntas, así como elaboraciones teóricas y metodológicas en torno a lo visual y sus tensiones y diálogos con el campo de los estudios visuales.

\footnotetext{
* Profesora de la Facultad de Ciencias Sociales de la Pontificia Universidad Javeriana, Bogotá, Colombia.
} 


\section{DERROTEROS DE LO “VISUAL” EN AMÉRICA LATINA}

El campo denominado "estudios visuales" emerge en el espacio abierto por movimientos intelectuales como el llamado "giro cultural" de finales de los años ochenta (que contribuyó igualmente a abrirle lugar a campos como los estudios culturales) y posteriormente el "giro pictórico", aunados al vertiginoso desarrollo tecnológico de las dos últimas décadas.

En el primero de estos giros se privilegiaron la lingüística, la semiótica, la retórica y varios modelos de "textualidad" en la reflexión crítica sobre el arte, los medios de comunicación y otras formas culturales (Mitchell, 2009, p. 19). El giro pictórico, de otra parte, implicaba

(...) el descubrimiento de que la actividad del espectador (la visión, la mirada, el vistazo, las prácticas de observación, vigilancia y placer visual) puede constituir un problema tan profundo como las varias formas de lectura (desciframiento, decodificación, interpretación, etc.) y que puede que no sea posible explicar la experiencia visual, o el "alfabetismo visual," basándose solo en un modelo textual. Lo mas importante es el descubrimiento de que, aunque el problema de la representación pictórica siempre ha estado con nosotros, ahora su presión, de una fuerza sin precedentes, resulta ineludible en todos los niveles de la cultura, desde las más refinadas especulaciones filosóficas a las más vulgares producciones de los medios de masas. Las estrategias tradicionales de contención ya no parecen servir y la necesidad de una crítica global de la cultura visual parece ineludible. (Mitchell, 2009, p. 23)

Las implicaciones de estos nuevos modos de interrogar las imágenes desbordan, paradójicamente, el espacio de las imágenes mismas, abren un interesante terreno de indagaciones inter y transdisciplinares para incluir nuevas preguntas sobre el rol del espectador, sobre la mirada en tanto hecho históricamente situado y cruzado por relaciones de poder, sobre los aparatos de visión y su multiplicación en el espacio de la vida cotidiana, sobre las prácticas del ver, sobre la invisibilidad y el ocultamiento, sobre la vigilancia y el panoptismo, y sobre las maneras como se desancla la imagen de su superficie bidimensional para habitar en pantallas, en espacios, en cuerpos, etc., implicando de esta manera a los demás sentidos y construyendo complejas experiencias sensoriales.

Estas indagaciones, desde luego, han sido parte de las agendas críticas en América Latina incluso desde antes de la emergencia tanto del campo llamado "estudios visuales", como de su aparición institucional. Este interés en lo visual es, sin embargo, casi paradójico, ya que la investigación con/sobre imágenes ha ocupado en general un espacio más bien minoritario dentro de las disciplinas de las ciencias sociales, concebidas como "disciplinas de palabras" (Mead, 1995), en las cuales la imagen tiene con frecuencia un papel subordinado frente al texto escrito. Incluso los objetos, las obras de arte y la fotografía han sufrido este mismo tratamiento:

Las representaciones en imágenes -las figuras de santos y vírgenes en iglesias medievales o coloniales, los grabados y pinturas, primero; la fotografía después- han ingresado a la investigación social con sentidos múltiples: como fuentes de datos, como objetos de estudio, como indicios de climas culturales de época, de mentalidades y de sistemas de significación. (Jelin, 2012, p. 56) 
Jesús Martín-Barbero irá más allá para afirmar que en el rechazo de los intelectuales de la cultura comunicacional en particular:

(...) hay algo más que un déficit de legitimidad académica que padece un "objeto". Parece más bien que sociólogos y antropólogos percibieran oscuramente el estallido de las fronteras que ella entraña, incluidas las de sus campos de estudio, por la configuración de objetos móviles, nómadas, de contornos difusos, imposibles de encerrar en las mallas de un saber positivo y rígidamente parcelado. (2002a, pp. 256-257)

En contextos muy particulares, como el de Colombia, el propio Martín-Barbero, por ejemplo, se refiere al "mal de ojo" que impide que los intelectuales consideren ciertos artefactos como la televisión, sus dinámicas, sus audiencias y estéticas, entre otros temas, como dignos de una reflexión seria y pertinente, a diferencia de países como Chile o Brasil (1997)¹.

Para Martín-Barbero, el campo visual es una pieza central en un nuevo sensorium que se articula a lo largo de las décadas de los ochenta y los noventa a partir de la emergencia del discurso multicultural y del desarrollo de nuevos actores y formas de comunicación, aunadas a las presiones tanto del mercado como de las políticas culturales en la región. En este sentido, la imagen (así como lo sonoro) constituye un espacio clave de "experimentación-simulación" (2002b, p. 20), es decir, un campo de batalla donde se disputan permanentemente nociones de identidad y pertenencia en medio de un panorama caracterizado por la dispersión y el mercado (Martín-Barbero y Ochoa, 2005). A esto parece apuntar el trabajo de Beatriz Sarlo Escenas de la vida posmoderna. Intelectuales, arte y videocultura en la Argentina (1994) al integrar en su crítica artefactos y prácticas como el centro comercial, el videoclip y el zapping como formas de aproximación a la cultura y la política de la era menemista. El zapping, en particular, constituye una práctica paradójica:

(...) demasiadas imágenes y un gadget relativamente sencillo, el control remoto, hacen posible

el gran avance interactivo de las últimas décadas que no fue producto de un desarrollo tec-

nológico originado en las grandes corporaciones electrónicas sino en los usuarios comunes y

corrientes. Se trata, claro está, del zapping. (1994, p. 59)

Para Sarlo, el zapping le permite al espectador recomponer las imágenes televisivas, dispersando su atención y recreando novedosos montajes ${ }^{2}$, aunque siempre dentro de los parámetros que dictan las industrias que producen tales imágenes; en otras palabras, la libertad del espectador es la libertad del mercado.

Néstor García-Canclini, por su parte, rearticula y actualiza algunos de estos debates en un texto más reciente centrado en el desequilibrio en la organización transnacional de las representaciones e imágenes en las artes y las industrias culturales, postulando además la necesidad de pensarla conjuntamente con la configuración geopolítica de los saberes (2007, p. 40, énfasis en el original). De manera no muy distinta, Daniel Mato (2003) señalaba en la década de los 2000 el desequilibrio en la visibilidad de la producción intelectual realizada en América Latina, en castellano, con respecto a la producción intelectual en lengua inglesa, que tiene más facilidades de circulación y mayor visibilidad. El propio Mato indicaba en ese entonces la necesidad de incorporar al campo académico "otros tipos de prácticas de carácter reflexivo y que se relacionan con los movimientos sociales (e.j. feminista, indígena, afrolatinoamerica- 
no, de derechos humanos, etc.) y/o con las artes" (2003, p. 80) y que él denomina prácticas intelectuales en cultura y poder, que tienen el objeto de descentrar y abrir la producción de conocimiento de las instituciones académicas y sus circuitos de visibilización, centrados en el artículo académico, para incluir otros artefactos (visuales, por ejemplo) con mayor capacidad de intervención.

A pesar de estas dificultades, motivadas tanto por los prejuicios que rodean la imagen, así como posiblemente por la escasez de herramientas teóricas y metodológicas, resulta notable el aporte pionero de los sociólogos argentinos Elizabeth Jelin ${ }^{3}$ y Pablo Vila, y la fotógrafa Alicia D’Amico, cuyo trabajo, Podría ser yo. Los sectores populares en imagen y palabra (1986), es un ejemplo de una investigación que se desprende del mero análisis de las imágenes para usarlas más bien como modo de intervención, como una herramienta para estimular a los actores sociales a aprehender sus propias prácticas. Podría ser yo... es la culminación de un proyecto sobre la vida cotidiana de un número de actores sociales realizado en el contexto de la dictadura en Argentina, preconizando trabajos más recientes, como los de Mariana Giordano ${ }^{4}$ y Alejandra Reyero, que "devuelven" fotografías etnográficas a los sujetos que pretenden representar -nativos chaqueños, en este caso, o el de Ludmila da Silva", que "devuelve" fotografías de centros clandestinos de detención a quienes sufrieron la experiencia de detención (da Silva, Giordano y Jelin, 2010)-, vinculando imagen, memoria e identidad, y que corresponden con la intencionalidad de los estudios visuales de trabajar no solo con, sino a través de las imágenes.

Ejemplos de esta apuesta particular de trabajo en el contexto colombiano son los trabajos de Zenaida Osorio Personas ilustradas: la imagen de las personas en la iconografía escolar colombiana (2001) y Haga como que: la violan, le pegan (2007), que examinan repertorios icónicos de la vida cotidiana -textos escolares, noticias de periódicos sobre diversas formas de violencia contra las mujeres, a los que se sumaron revistas, libros de bolsillo y fascículos dirigidos a las mujeres, con el objeto de hacer una suerte de genealogía capaz de desnaturalizar aspectos de raza, clase y género, entre otros, que permean la imaginería local. Estos y otros de sus trabajos se distribuyen gratuitamente vía web (diasfrios.org).

De igual manera, se pueden señalar algunas similitudes entre este ejercicio de devolución de imágenes a los sujetos representados y los trabajos del artista José Alejandro Restrepo en Transhistorias (2001), o Cuerpo Gramatical (2006), así como el de la "Sociología de la imagen" de Silvia Rivera Cusicanqui en el sentido de resignificar, relocalizar y reactualizar imágenes del pasado en el tiempo presente. El trabajo de Restrepo, por su parte, busca trazar continuidades y discontinuidades entre formas de violencia pasadas y presentes a partir de la contraposición de series de imágenes tanto históricas como contemporáneas. Rivera Cusicanqui resalta, por otra parte, la importancia de analizar la forma como las culturas visuales, en tanto pueden aportar a la comprensión de lo social, se han desarrollado con una trayectoria propia, que a la vez revela y reactualiza muchos aspectos no conscientes del mundo social.

Así, la sociología de la imagen de Rivera Cusicanqui revisita la carta ilustrada Primer Nueva corónica y buen gobierno (1612-1615), dirigida por Guamán Poma de Ayala al rey de España bajo la premisa de que es necesario tomar distancia de la palabra, que considera como un registro ficcional, plagado de eufemismos que velan la realidad en lugar de designarla y que, en este 
sentido, ocultan conflictos culturales irresueltos, como el racismo y la desigualdad. Para Rivera Cusicanqui, las imágenes, en contraste, pueden ofrecer otras interpretaciones y narrativas sociales alternativas, a la vez que iluminan pasajes y sentidos no censurados por la lengua oficial:

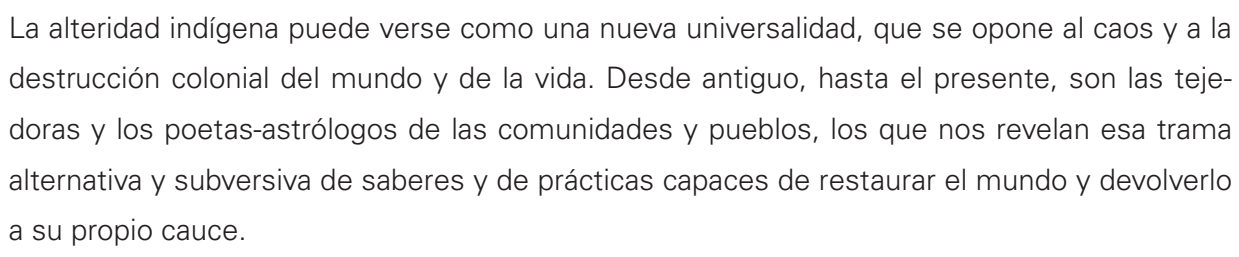

En efecto, en contextos de censura, "lo artístico-cultural se convierte en el campo sustitutivo -desplazatorio y compensatorio- que permite trasladar hacia figuraciones indirectas lo prohibido por el discurso oficial" (Richard, 2006, p. 104). Bajo esta premisa, la llamada Escena de Avanzada chilena:

(...) se vale del corte neovanguardista para conjugar un triple deseo de politización del arte, de radicalidad formal y de experimentalismo crítico. La Escena de Avanzada reformuló, desde fines de los años 70, mecánicas de producción creativa que cruzaron las fronteras entre los géneros (las artes visuales, la literatura, la poesía, el video y el cine, el texto crítico) y que ampliaron los soportes técnicos del arte al cuerpo vivo y a la ciudad: el cuerpo, en el arte de la performance, actuó como un eje transemiótico de energías pulsionales que liberaron -en tiempos de censura- márgenes de subjetivación rebelde, mientras que las intervenciones urbanas buscaban alterar fugazmente las rutinas callejeras con su vibrante gesto de desacato al encuadre militarista que uniformaba el cotidiano. (Richard, 2009)

La apuesta de esta escena artística se caracteriza por su noción de producción colectiva del arte, la erosión de los límites entre el arte y sus públicos, así como su énfasis en "la materialidad indisciplinada de los cuerpos y el deseo" (Jenckes y Dove, 2009, p. 103). Más recientemente, y frente a la emergencia del campo de los estudios visuales, Richard ha comentado cómo estos tensionan positivamente la posición de centralidad de la producción artística en relación con otras formas de producción visual, aunque argumenta que las artes producen lo que ella llama "vibraciones intensivas" que retan los lenguajes uniformes del diseño, la publicidad y los medios ${ }^{6}$, inquietando (más que aquietando) la mirada (Richard, 2007, p. 106).

\section{ALGUNOS ANCLAJES INSTITUCIONALES DE LOS ESTUDIOS DE LA IMAGENY LOS ESTUDIOS VISUALES}

Hay un interés renovado por los estudios inter o transdisciplinares de la imagen en la región, que se hace perceptible a partir del número creciente de publicaciones, foros y centros dedicados a este objeto. De otra parte, el discurso de los estudios visuales parece haber permeado la labor intelectual en disciplinas en las que la imagen es central, como la antropología visual o la historia del arte. Esta sección, que no tiene pretensión alguna de exhaustividad, como se ha señalado más arriba, explora algunas líneas de fuerza que articulan actualmente el discurso de lo visual en algunos países de la región y le dan un anclaje institucional. 
En Argentina resulta notable el trabajo conjunto del Centro de Estudios de la Imagen Sans Soleil (CEISS) y el Área de Antropología Visual de la Universidad de Buenos Aires (AAV). El CEISS es un centro de estudios independiente con interés en el estudio de la imagen, que se origina en Barcelona en 2011 y que ha creado una serie de iniciativas en su proceso de consolidación, como la editorial Sans Soleil Ediciones y diversos proyectos de investigación. En 2013, el CEISS se une a los equipos de investigación Irudi y AVV (Área de Antropología Visual) de la Universidad de Buenos Aires (UBA), iniciando un auspicioso ciclo que incluye actividades de formación, eventos, publicaciones y proyectos de investigación. El equipo de investigación IRUDI aúna investigadores provenientes tanto de la antropología como de la historia del arte, y aborda problemáticas referidas al estudio de la imagen desde el diálogo entre ambas disciplinas.

Este equipo edita la revista-blog 2.0 E-imagen, de actualización constante y que le otorga un lugar prioritario a la imagen. El objetivo de E-imagen es la divulgación amplia y dinámica de las investigaciones del equipo apostándole a los medios digitales como formas de comunicación del trabajo académico, en lugar de recurrir al formato tradicional de revista:

La idea de una revista más cercana a la lógica y dinámica de un blog nace con el objetivo de mantener una conexión mucho más fluida con la difusión y mucho más compleja en la investigación, que nos permita trabajar con textos que se articulan con plataformas como Tumblr, Flickr, Facebook o Twitter, así como foros y experiencias en línea en tiempo real. Una práctica generalmente ausente en los artículos clásicos, en formato pdf, que deben responder a otro tipo de requisitos y diseños y presentan dificultades técnicas de conexión y edición.

Por su parte, Tramas-Red de alfabetización audiovisual y formación ciudadana integró tres proyectos desarrollados e implementados por el Área Educación de FLACSO Argentina, el Centro de Investigación y desarrollo de la educación (CIDE) de Chile y el Foro Educativo de Perú para la consolidación de una red regional de alfabetización audiovisual y formación ciudadana. Este proyecto implementa talleres de formación para docentes sobre medios, imágenes y ciudadanía, ofrece recursos y guías de trabajo que contribuyan al trabajo en el aula con materiales audiovisuales y a la formación ciudadana de los docentes de los tres países y contribuye con la difusión de artículos de investigación.

Entre las actividades de este proyecto, los seminarios internacionales Educar la mirada se han centrado en la discusión sobre las dinámicas de producción, consumo y circulación de imágenes y los desafíos para la educación, vinculando preocupaciones de los estudios visuales sobre la posición del espectador con aspectos pedagógicos. Algunas de estas discusiones han sido consignadas en el libro Educar la mirada. Políticas y pedagogías de la imagen (Dussel y Gutiérrez, 2006), que reúne textos conocidos de autores como Carlos Monsiváis, Rossana Reguillo o Nelly Richard, así como textos que relatan y analizan experiencias concretas y discuten los alcances y limitaciones de alfabetización audiovisual. Otras actividades que se realizan en el marco de Tramas incluyen seminarios sobre cultura visual y educación, alfabetización audiovisual, etnografía de la escuela y medios de comunicación.

Otras iniciativas de interés son la de la revista virtual Caiana, del Centro Argentino de Investigadores del Arte, dedicada a la historia del arte y cultura visual, promoviendo de esta forma 
cruces interdisciplinarios, y las Jornadas Interdisciplinarias sobre Estudios de Género y Estudios Visuales, que tuvieron lugar este año en la Universidad Nacional de Mar de Plata y que promueven este enfoque particular.

En Brasil, el grupo de investigación interinstitucional INARRA (Grupo de Pesquisa Imagens, Narrativas e Práticas Culturais), basado en el programa de posgrado de Ciencias Sociales de la Universidad Estatal de Rio de Janeiro, funciona desde 1994 y reúne estudiantes de pregrado, posgrado e investigadores interesados en la reflexión en torno a las narrativas visuales y su aplicación en antropología. Uno de los objetivos de INARRA es estimular el uso de imágenes en la investigación social en busca de nuevas posibilidades para la producción y transmisión de conocimiento. De esta forma, entre su producción se encuentran ensayos fotográficos, películas y textos sobre cine, e incluso una compilación multimedia, Imagens e narrativas (Peixoto y otros, 2012).

Por su parte, la Universidad Estatal Vale do Acaraú (UVA), a través de su Laboratorio de Memorias y Prácticas Cotidianas (LABOME), combina actividades de investigación, enseñanza y extensión con un énfasis en prácticas de archivo que incluyen documentación tanto oral (memorias y narrativas) como visual (entrevistas, documental, fotografía) relacionadas con las prácticas cotidianas. Muchos de los intereses del Laboratorio convergen en su evento Visualidades, que combina actividades académicas con proyecciones de documentales y exposiciones fotográficas.

Situados en una línea más cercana a los estudios visuales están el programa de Multimedios del Instituto de Artes y el Grupo de Trabajo Cultura Visual, Imagen e Historia, del posgrado en Historia y el Instituto de Artes, que organiza un seminario internacional de Cultura Visual e Historia de la Universidad de Campinas (Unicamp); el programa de posgrado en Artes Visuales de la Escuela de Bellas Artes (PPGAV) de la Universidad Federal de Río de Janeiro (UFRJ), que cuenta con una línea de investigación en imagen y cultura, apoyada por grupos de investigación interdisciplinares, entre los que se destaca el Núcleo Interdisciplinar de Estudios de la Imagen y el Objeto; y el Grupo de Estudios Visuales y Urbanos de la Universidad Federal de San Pablo (Unifesp), que data de 2007 y asocia antropología visual y urbana. La revista Domínios da Imagem, del Laboratorio de Estudios de los Dominios de la Imagen (LEDI) del Departamento de Historia de la Universidad Estatal de Londrina, por su parte, que se publica desde 2007, presenta también algunas afinidades al proyecto de los estudios visuales.

Finalmente, el programa de posgrado en Arte y Cultura Visual de la Universidad Federal de Goiás (PPGACV) presenta tres líneas de investigación: imagen, cultura y producción de sentido, poéticas visuales y procesos de creación, y culturas de la imagen y procesos de mediación. De igual forma, este programa organiza un seminario nacional de investigación en arte y cultura visual desde 2008.

Chile cuenta con el Centro de Estudios en Antropología Visual (CEAVI), un espacio académico que trabaja en conexión con el Núcleo de Antropología Visual de la Universidad Academia de Humanismo Cristiano (UAHC) en diferentes líneas de trabajo (investigación, docencia, realizaciones audiovisuales y extensión). El CEAVI trabaja concretamente sobre la representación 
visual de pueblos indígenas, las imágenes y la construcción del espacio doméstico y de las prácticas culturales e industriales asociadas a la cacería de ballenas. Uno de sus proyectos más consolidados y reconocidos es la Revista Chilena de Antropología Visual, publicación electrónica que cuenta con 23 números editados a la fecha.

También en Chile el Centro de Estudios Visuales mantiene una línea de producción académica desde 2009. Por esa misma época surge la plataforma de trabajo Contrafoco, que busca contribuir a:

(...) la investigación, análisis y difusión de diferentes propuestas de reflexión contemporánea en torno a la imagen y su vinculación con los desafíos teóricos y metodológicos de las ciencias sociales. Al mismo tiempo es un proyecto permanente, cuya perspectiva no se define desde una disciplina en particular, sino desde una serie de principios epistemológicos asociados a la visualidad, los cuales poseen un origen teórico y metodológico controvertido.

Contrafoco ha organizado a la fecha cuatro versiones del evento académico Territorios de la Imagen (desde 2008), el cual ha abierto discusiones en torno a los estudios visuales convocando a historiadores, antropólogos, artistas, críticos culturales y estetas. Cuenta actualmente con el primer número de la revista titulada también Territorios de la Imagen (2013).

El Instituto Mora, en México, tiene una línea de investigación en estudios de la imagen, al igual que un Laboratorio Audiovisual de Investigación Social (LAIS), definido como un espacio colectivo e interdisciplinario dedicado a la investigación social con imágenes y publicaciones desde mediados de los años noventa, como la compilación Imágenes e investigación social (Aguayo y Roca, 2005), que reúne las ponencias del Primer Congreso sobre Imágenes e Investigación Social (2002). De manera similar, el Instituto de Estudios Críticos 17 cuenta con una línea de estudios visuales y cursos sobre el tema.

Por su parte, la Universidad Autónoma de Nuevo León viene realizando el Simposio Internacional de Estudios Visuales desde 2006. Por último, en la Universidad Autónoma del Estado de México se ha creado el primer programa que emplea la denominación "estudios visuales" en América Latina, el cual tiene por objeto:

(...) formar capital humano de alto nivel de preparación en la producción artística y el análisis de los problemas de la visualidad contemporánea mediante el desarrollo de modelos propios de conceptualización que incidan en la producción, la pedagogía y la epistemología del arte.

En el marco de este programa, se organizó recientemente un foro internacional de estudios visuales bajo el lema La imagen como pensamiento (octubre de 2014).

Existen, desde luego, otros espacios institucionales con importantes reflexiones en torno a la imagen, como las maestrías en Antropología Visual de la Pontificia Universidad Católica de Perú (PUCP) -que ha realizado eventos bajo la rúbrica de los estudios visuales en 2004 y 2005- (Cánepa, 2010), y la de FLACSO-Andes, así como la mención en artes y estudios visuales de la maestría en Estudios de la Cultura de la Universidad Andina Simón Bolívar, ambas en Ecuador. En Colombia hay un interés creciente en la "antropología de lo visual", como la 
denominan Mónica Espinosa y Juana Schlenker en su presentación al dossier Antropología (y lo) Visual de la revista Antípoda, de la Universidad de los Andes (2009). Esta presenta una serie de aproximaciones que oscilan entre reflexiones sobre la antropología visual, cine documental, cine etnográfico, intervenciones artísticas y el ensayo fotográfico. Tal interés se evidencia, por ejemplo, en la producción que se consigna en el último número de la mencionada Revista Chilena de Antropología Visual, dedicado a la antropología visual en el país (y publicado en colaboración con la Universidad ICESI), o en la aparición de grupos como Obtura: Grupo de Estudios en Antropología Audiovisual, Kino Pravda (organizadores del I Encuentro de Antropología Visual en 2007), ambos de la Universidad Nacional de Colombia, o el semillero de antropología visual promovido desde la Universidad de los Andes.

Además de lo anterior, se han creado en los últimos años algunos grupos que usan el rótulo "estudios visuales", o que tienen posiciones cercanas a ese campo, tal como el grupo de investigación Estudios Visuales de la Pontificia Universidad Javeriana (PUJ) y la Universidad de los Andes, que convocó al presente dossier, así como al dossier Imagen y ciencias sociales de la revista Memoria y sociedad (2012-2013), y que ofrece cursos de nivel de maestría sobre el tema en el marco de los programas de Estudios Culturales de ambas instituciones. Otros grupos afines son el grupo de investigación interinstitucional Prácticas Culturales, Imaginarios y Representaciones, el Grupo Videns de la Universidad del Atlántico, el de investigación en Cultura, Imagen y Política en América Latina, de la Universidad de Chile, que vienen a sumarse a iniciativas regionales tales como la Red de Estudios Visuales Latinoamericanos, que cuenta a la fecha con tres encuentros internacionales realizados en México, o el mencionado CEAVI, que cuenta con investigadores asociados en varios países.

Un recuento más minucioso de los programas, los grupos, los eventos y las publicaciones excede por mucho, como se mencionó, el objeto de esta presentación. Resta concluir que esta publicación, así como muchas de las mencionadas más arriba y otras que se escapan de este recorrido, son muestra del dinamismo de este campo en la región. Lo que se propone aquí no es más que un punto de entrada, una invitación a realizar indagaciones más amplias.

\section{NOTAS}

1 De esta forma, buena parte de la producción académica sobre violencia se ha centrado menos en la imagen, y más en factores políticos, sociales o económicos. Las dinámicas audiovisuales del periodo presidencial de Álvaro Uribe (2002-2010), sin embargo, generaron un renovado interés en la imagen y sus usos ideológicos. Ver López de la Roche, 2014; Cabrera 2013; Gordillo 2014, así como los artículos de Yepes y Olaya, y Herrera, contenidos en el presente dossier.

2 Ver también Crary (2008a; 2008b), así como la crítica que le hace Mitchell (2009).

3 Elizabeth Jelin pertenece al Núcleo de Estudios sobre la Memoria del IDES (Instituto de Desarrollo Económico y Social), donde se han desarrollado interesantes investigaciones sobre el tema en conexión con las imágenes. Ver Feld y Stites Mor (2009).

4 Mariana Giordano es directora del Núcleo de Estudios y Documentación de la Imagen, dependiente del Instituto de Investigaciones Geo Históricas CONICET-UNNE. 
5 Ludmila da Silva es investigadora de la Universidad Nacional de Córdoba (UNC) y del CONICET en el Museo de Antropología-UNC. Se desempeña actualmente como directora del Archivo y Comisión Provincial de la

Memoria en Córdoba, Argentina.

6 Al respecto ver Arfuch (2009).

\section{REFERENCIAS}

Aguayo, Fernando y Roca, Lourdes, coords. Imágenes e investigación social. México: Instituto Mora, 2005.

Arfuch, Leonor y Devalle, Verónica, comps. Visualidades sin fin. Imagen y diseño en la sociedad global. Buenos Aires: Prometeo Libros, 2009.

Cabrera, Marta. "Espectáculos de estado. Visibilizando al enemigo en la seguridad democrática". En Violencia, sociedad y memoria, Alejandro Castillejo y Fredy Leonardo Reyes. Bogotá: USTA, 2013. 67-81.

Cánepa, Gisela. “Reflexiones desde el método: desplazamiento, participación y performance como estrategias para el pensamiento/acción críticos", Tabula Rasa, Bogotá, vol. 12 (2010): 273-291.

Crary, Jonathan. Las técnicas del observador. Visión y modernidad en el siglo XIX. Murcia: CENDEAC, 2008b.

Crary, Jonathan. Suspensiones de la percepción. Atención, espectáculo y cultura moderna. Madrid: Akal, 2008a.

da Silva, Ludmila, Giordano, Mariana y Jelin, Elizabeth, eds. Fotografía e identidad. Captura por la cámara, devolución por la memoria. Buenos Aires: Nueva Trilce, 2010.

Dussel, Inés y Gutiérrez Daniela, comps. Educar la mirada: políticas y pedagogías de la imagen. Buenos Aires: Manantial, OSDE, 2006.

Espinosa, Mónica y Schlenker, Juana. "Antropología (y lo) visual." Antípoda. Revista de Antropología y Arqueología, vol. 9 (2009): 11-14.

Feld, Claudia y Stites Mor, Jessica, comps. El pasado que miramos. Memoria e imagen ante la historia reciente. Buenos Aires: Paidós, 2009.

García-Canclini, Néstor. “El poder de las imágenes. Diez preguntas sobre su redistribución internacional". Estudios Visuales, vol. 4 (2007): 36-55.

Gordillo, Claudia. Seguridad Mediática: la propaganda militarista en la Colombia contemporánea. Bogotá: Corporación Universitaria Minuto de Dios. Facultad Ciencias de la Comunicación, 2014.

Jelin, Elizabeth y Vila, Pablo. Podría ser yo. Los sectores populares en imagen y palabra. Buenos Aires: Ediciones de la Flor/Cedes, 1986.

Jelin, Elizabeth. "La fotografía en la investigación social: algunas reflexiones personales" Memoria y sociedad, vol. 16, núm. 33 (2012): 55-67.

Jenckes, Kate y Dove, Patrick "Estética". En Diccionario de Estudios Culturales Latinoamericanos, coords. Mónica Szurmuk y Robert McKee Irwin. México: Siglo XXI Editores, Instituto Mora, 2009. 101-105.

López de la Roche, Fabio. Las ficciones del poder. Patriotismo, medios de comunicación y reorientación afectiva de los colombianos bajo Uribe Vélez (2002-2010). Bogotá: Penguin Random House, 2014.

Martín-Barbero, Jesús. "Televisión o el mal de ojo de los intelectuales". Comunicación y sociedad, vol. 29 (1997): 11-22. 
Martín-Barbero, Jesús. "Una agenda para el cambio de siglo". En Oficio de cartógrafo. Travesías latinoamericanas de la comunicación en la cultura. México: FCE, 2002a. . 256-272.

Martín-Barbero, Jesús. "Tecnicidades, identidades, alteridades: des-ubicaciones y opacidades de la comunicación en el nuevo siglo". Diálogos de la comunicación, vol. 64, (2002b): 9-24.

Martín-Barbero, Jesús y Ochoa, Ana María. "Políticas de multiculturalidad y desubicaciones de lo popular". En Cultura, política y sociedad. Perspectivas latinoamericanas, Daniel Mato. Buenos Aires: CLACSO, 2005. 181-197.

Mato, Daniel. "Estudios y otras prácticas latinoamericanas en cultura y poder: crítica de la idea de estudios culturales latinoamericanos y propuesta para la visibilización de un campo más amplio, transdisciplinario, crítico y contextualmente referido." En Estudios culturales latinoamericanos: retos desde y sobre la región andina, ed. Catherine Walsh. Quito: Universidad Simón Bolívar, Abya. Yala, 2003. 73-111.

McPhail Fanger, Elsie. "La imagen como objeto interdisciplinario". Razón y palabra, 77, 2011. www. razonypalabra.org.mx (acceso 8 de septiembre de 2014)

Mead, Margaret. "Visual anthropology in a discipline of words." En Principles of Visual Anthropology, ed. P. Hockings. Berlin y New York: Mouton de Gruyter, 1995.

Mitchell, William J. Thomas. Teoría de la imagen. Ensayos sobre la representación verbal y visual. Madrid: Akal, 2009.

Osorio, Zenaida. Haga como que: la violan, le pegan. Bogotá: Universidad Nacional de Colombia, 2007.

Osorio, Zenaida. Personas ilustradas: la imagen de las personas en la iconografía escolar colombiana. Bogotá: Colciencias, 2001.

Peixoto, Clarice E. y otros. Imagens \& Narrativas. Río de Janeiro: INARRA, Imagens, Narrativas e Práticas Culturais (PPCIS-UERJ), 2012.

Restrepo, José Alejandro. Cuerpo gramatical: cuerpo, arte y violencia. Bogotá: Uniandes, 2006.

Restrepo, José Alejandro. Transhistorias. Historia y mito en la obra de José Alejandro Restrepo. Bogotá: Banco de la República, 2001.

Richard, Nelly. "Estudios visuales, políticas de la mirada y crítica de las imágenes". En Fracturas de la memoria. Arte y pensamiento crítico. México: FCE, 2007. 95-106.

Richard, Nelly. "La Escena de Avanzada y su contexto histórico-social". En Copiar el Edén. Arte reciente en Chile, ed. G. Mosquera. Santiago: Editorial Puro Chile, 2006, 103-111.

Richard, Nelly. "Lo político en el arte: arte, política e instituciones", e-misferica 6.2. [En línea], 2009. http://hemisphericinstitute.org/hemi/en/e-misferica-62/richard (Acceso: 8 de septiembre de 2014).

Rivera Cusicanqui, Silvia. "Sociología de la imagen." http://chixinakax.wordpress.com/2010/07/23/ sociologia-de-la-imagen/ (Acceso: 8 de septiembre de 2014).

Sarlo, Beatriz. Escenas de la vida posmoderna. Intelectuales, arte y videocultura en la Argentina. Buenos Aires: Ariel, 1994.

\section{Páginas web}

17, Instituto de Estudios Críticos. http://17edu.org/

CAIANA. http://www.caia.org.ar/caiana.php

Centro de estudios de la imagen Sans Soleil (CEISS). http://www.ceiss.es/

Centro de Estudios en Antropología Visual (CEAVI). http://www.ceavi.cl/

Centro de Estudios Visuales. http://centroestudiosvisuales.wordpress.com/ 
Contrafoco. http://www.contrafoco.cl/

Domínios da Imagem. http://www.uel.br/revistas/uel/index.php/dominiosdaimagem (Acceso el 13 de febrero de 2015)

e-imagen. http://www.e-imagen.net

Grupo Videns. http://grupovidens.blogspot.com/

INARRA-Grupo de Pesquisa Imagens, Narrativas e Práticas Culturais. http://www.inarra.com.br/ apresentacao/

Instituto Mora. http://www.mora.edu.mx/Investigacion/Principal/c_estudios_imagen.html

IRUDI-estudios de la imagen: antropología, medio, visualidad. http://www.irudi-uba.com

Maestría en antropología visual (FLACSO-Andes). http://www.flacsoandes.edu.ec/antropologia_ visual/

Maestría en antropología visual (PUCP). http://posgrado.pucp.edu.pe/maestrias/ciencias-sociales/ antropologia-visual/

Maestría en estudios visuales (UAEM). http://www.uaemex.mx/planes/verpos.html?ver=fa_m_ ev.pdf

Memoria y Sociedad. http://memoriaysociedad.javeriana.edu.co/

Obtura: Grupo de Estudios en Antropología Audiovisual. http://obturageaa.wordpress.com/

Programa de posgrado en artes visuales (UFRJ). http://www.ppgav.eba.ufrj.br/programa/ apresentacao/

Programa de posgrado en multimedios, Unicamp. http://www.unicamp.br/unicamp/ ensenanza-y-investigacion/postgrado/programas-de-postgrado/ciencias-humanas-sociales-yarte-6? language $=$ es

Red de Estudios Visuales Latinoamericanos http://revlat.blogspot.com/

Revista Chilena de Antropología Visual. http://www.rchav.cl/

Seminario nacional de investigación en arte y cultura visual (PPGACV). http://projetos.extras.ufg.br/ seminariodeculturavisual/wordpress/?page_id=411

Tramas-Red de alfabetización audiovisual y formación ciudadana. http://tramas.flacso.org.ar/ presentacion

Visualidades. http://www.uvanet.br/hotsite_visualidades/

Zenaida Osorio. www.diasfrios.org 